\title{
A Case Study of Teaching the Concept of Differential in Mathematics Teacher Training
}

\author{
Le Thai Bao Thien Trung \\ Department of Mathematics and Computer sciences, Ho Chi Minh City University of Education, Vietnam
}

ABSTRACT-

In high schools of Viet Nam, teaching calculus includes the knowledge of the real function with a real variable. A mathematics educator in France, Artigue (1996) has shown that the methods and approximate techniques are the centers of the major problems (including number approximation and function approximation...) in calculus. However, in teaching mathematics in Vietnam, the problems of approximation almost do not appear. With the task of training mathematics teachers in high schools under the new orientations, we present a part of our research with the goal of improving the contents and methods of teacher training.

Keywords: Teacher training, calculus, the problems of approximation, differential, teacher students

Date of Submission: 16 February 2017

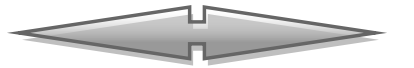

Date of Accepted: 05 March 2017

\section{INTRODUCTION}

In high school mathematics programs of Vietnam, the calculus is taught with the greatest amount of time compared to other subjects such as algebra and geometry. The analytic knowledge will be considered as the platform for students of engineering sciences and economics in colleges and universities for further studies in mathematics and calculus courses in mathematics application of these educational levels.

To determine the approximate problems in teaching calculus, we refer to the textbook "Calculus": Early Transcedentals (7th) by James Stewart (2012). This work is the best-selling in the United States (US) and has a range of effect on teaching calculus at high school level in the US and some of the world's universities. We found it necessary to introduce the idea of authors.

Stewart (2012) started his preface by a quote from Polya:

A great discovery solves a great problem but there is a grain of discovery in the solution of any problem. Your problem may be modest; but if it challenges your curiosity and brings into play your inventive faculties, and if you solve it by your own means, you may experience the tension and enjoy the triumph of discovery.

\section{GEORGE POLYA}

Stewart (2012) oriented to draft a curriculum to help students explore calculus because:

Newton undoubtedly experienced a sense of triumph when he made his great discoveries. I want students to share some of that excitement. (Stewart 2012, Preface, p. xi).

The author argues that the ordinary calculus teaching should aim to basically make the learner understand the concept thanks to the observations on the graph, and the experiments on algebraic expressions.

I think that nearly everybody agrees that this should be the primary goal of calculus instruction. In fact, the impetus for the current calculus reform movement came frome the Tulane Conference in 1986, which foemualted as their first recommendation: Focus on conceptual understanding.

I have tried to implement this goal through the Rule of Three: "Topics should be presented geometrically, numerically, and algebraically." Visualization, numerical and graphical experimentation, and other approaches have changed how we teach conceptual reasoning in fundamental ways. The Rule of Three has been expanded to become the Rule of Four by emphasizing the verbal, or descriptive, point of view as well. (Stewart 2012, Preface, p. xi).

To illustrate teaching points through the experiment of Stewart (2012), we take the example of the concept of differential in this curriculum.

Students can approximate a nonlinear function in a small range of the independent variable by a linear function, therefore, Stewart (2012) proposed through an experiment on the graph with the help of a graphing software. Example 1. The more we zoom in, the more the parabola looks like a line. In other words, the curve becomes almost indistinguisable from its tangent line. 

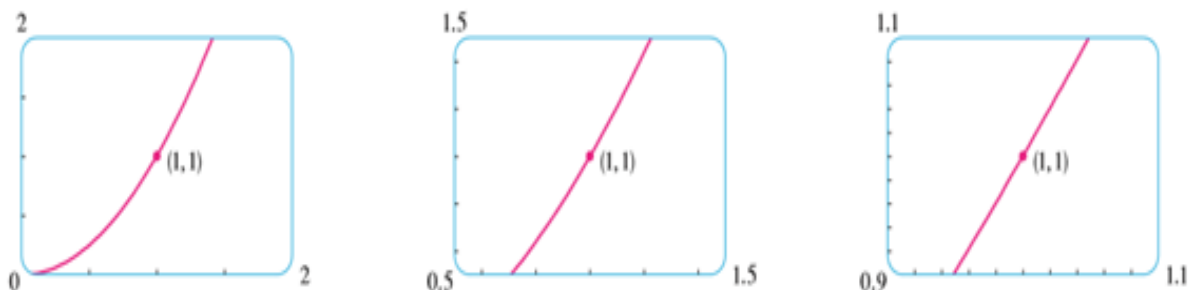

FIGURE 1

Zooming in toward the point $(1,1)$ on the parabola $\mathrm{y}=\mathrm{x}^{2}$ (Stewart 2012, p. 144)

EXAMPLE 1: Find the linearization of the function $f(x)=\sqrt{x+3}$ at $a=1$ and use it approximate the numbers $\sqrt{3.98}$ and $\sqrt{4.05}$. Are these approximations overestimates or underestimates?

After finding tangential equation of $f$ at the point $(1,2), L(x)=\frac{7}{4}+\frac{x}{4}$ and it was used to calculate approximate values, then the author suggested an experiment on the portable computer:

\begin{tabular}{|c|c|c|c|}
\hline & $x$ & From $L(\mathrm{x})$ & Actual value \\
\hline$\sqrt{3.9}$ & 0.9 & 1.975 & $1.97484176 \ldots$ \\
$\sqrt{3.98}$ & 0.98 & 1.995 & $1.99499373 \ldots$ \\
$\sqrt{4}$ & 1 & 2 & $2.00000000 \ldots$ \\
$\sqrt{4.05}$ & 1.05 & 2.0125 & $2.01246117 \ldots$ \\
$\sqrt{4.1}$ & 1.1 & 2.025 & $2.02484567 \ldots$ \\
$\sqrt{5}$ & 2 & 2.25 & $2.23606797 \ldots$ \\
$\sqrt{6}$ & 3 & 2.5 & $2.44948974 \ldots$ \\
\hline
\end{tabular}

Observing this fact allowed to state: "Notice from this table, and also from Figure 2, that the tangent line approximation gives good estimates when $x$ is close to 1 but the accuracy of the approximation deteriorates when $x$ is farther away from 1." (Stewart 2012, page 252).

After defining differentials $d x$ and $d y$ with $d y=f^{\prime}(x) d x$ and the geometric significance of the differential is clarified.

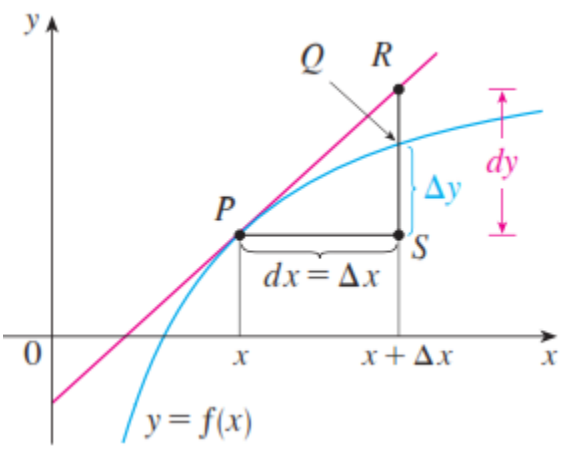

FIGURE 2 (Stewart 2012, page 253)

Differential $\mathrm{dx}$ can be interpreted as $\Delta x$, a small change in the value of the variable $\mathrm{x}$ (increment of $\mathrm{x}$ ).

When $\Delta x$ is changed, dy is the change in y-coordinate of the curve $\mathrm{y}=\mathrm{f}$ (x) so $\Delta y=f(x+\Delta x)-f(x)$ (increments of $\mathrm{y}$ ).

Meanwhile, the differential dy is the change in $\mathrm{y}$-coordinate of the tangent at the point with $\mathrm{x}$ coordinate.

From the visual image, we state: $\Delta \mathrm{y} \approx \mathrm{dy} \Leftrightarrow \mathrm{f}(\mathrm{x}+\Delta \mathrm{x})-\mathrm{f}(\mathrm{x}) \approx f^{\prime}(x) \Delta \mathrm{x}$ or $\mathrm{f}(\mathrm{x}+\Delta \mathrm{x}) \approx \mathrm{f}(\mathrm{x})+f^{\prime}(x) \Delta \mathrm{x}$ 
The final equality has been said in thought: the graph of function is close to its tangent in the vicinity of the contacts. Concerning the teaching of the concepts of calculus in secondary education in Vietnam, our research, conducted through the thesis of Chung Thi Kim Hanh (2015) shows that, with the presentation of current textbooks and how to teach the concept of the differential in Vietnam, the students did not understand the meaning of differential and the role of this concept. Also, in his study of teaching calculus in high schools, Tran Luong Cong Khanh (2006) also stated: After proving $\mathrm{dx}=\Delta \mathrm{x}$, textbooks do not mention dx again and left a big secret for dx notation.

\section{METHODOLOGY AND RESULTS}

To introduce students to teaching methods to solve the problems, we have asked students to read and summarize the content themselves in the curriculum.

We chose to organize an experiment around teaching the concept of differential.

The experiment was held through the following stages:

- Phase 1: investigate the perceptions of 3rd year students about the concept of differential. (Level 1)

- Phase 2: A group (2 students) works on a problem-solving situation.

- Phase 3: Introduce the concept of differential through its geometric meaning again.

- Phase 4: Organize the class discussion on how to teach the concept in secondary schools.

\subsection{Stage 1: Investigate the perceptions of 3rd year teacher students about the concept of differential}

The goal of this investigation is to:

- Observe the evolution in the understanding of the 3rd year teacher students about the concept of differential compared to high school students.

- Help students realize the difficulties any learner can always encounter when comprehending this concept if it is not learnt through a situation which brings its meaning.

The contents of the questionnaire are as follows:

Question 1. Given the following facts: the function $y=f(x)=\sqrt{x}$, the value $\mathrm{x}_{0}=4$ and $\Delta x=0,02$

a) You are asked to write a short paragraph to explain to a grade 11 student to know $\Delta x=0,02$ what it means.

b) Please calculate $d x$ and $d y$. If $d x$ and dy are calculated, please write a short paragraph to explain to a grade 11 student to know what they mean. If $\mathrm{dx}$ and dy are not calculated, please explain why you cannot answer.

c) Take out the two different exercises related to the facts given.

Question 2. Do not use a portable computer; display how to calculate $\sqrt{4,001}$ in detail with the highest accuracy if possible. If you cannot calculate, please tell us why.

Experimental results

Question 1a)

\begin{tabular}{|c|c|c|c|}
\hline Answer & $\begin{array}{c}\text { Denotes the difference (or increment) between } \mathrm{x} \\
\text { and } \mathrm{x}_{0}, \text { or } \Delta \mathrm{x}=\mathrm{x}-\mathrm{x}_{0}\end{array}$ & $\begin{array}{c}\text { No answer or answers that they } \\
\text { misunderstood }\end{array}$ & Sum \\
\hline & $15(48 \%)$ & $16(52 \%)$ & 31 \\
\hline
\end{tabular}

We were very surprised when more than half of students in the survey indicated that they did not understand $\mathrm{dx}$ symbol. For example, a student did not know what it (dx) means (though remember the name of this symbol).

Câu 1. Cho các dữ kiện sau: hàm số $y=f(x)=\sqrt{x}$, giá trị $x_{0}=4$ và $\Delta x=0,02$.

a) Bạn hãy viết một đoạn ngắn để giài thich cho một HS lớp 11 biết $\Delta x=0,02$ có nghĩa là gì?

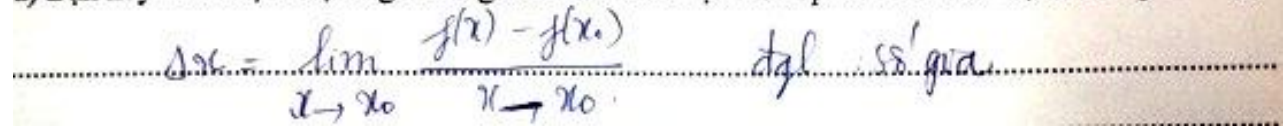

Question $1 b$ )

\begin{tabular}{|c|c|c|c|}
\hline $\begin{array}{c}\text { Answers for } \\
\text { calculating } \mathrm{dx}\end{array}$ & $\mathrm{dx}=\Delta \mathrm{x}$ & $\begin{array}{c}\text { No answer or answers that } \\
\text { they do not know what is } \mathrm{dx}\end{array}$ & $\begin{array}{c}\text { Sum } \\
26(84 \%)\end{array}$ \\
\hline $\begin{array}{c}\text { Answers for } \\
\text { calculating dy }\end{array}$ & $\begin{array}{c}\text { Using the formula } d y=f^{\prime}(x) d x \text { or calculate the } \\
\text { correct value of differential }\end{array}$ & $\begin{array}{c}\text { No answer or using the } \\
\text { formula is not related to } \\
\text { differential }\end{array}$ & $\begin{array}{c}\text { Sum } \\
\end{array}$ \\
& $d y=f^{\prime}(x) d x=\frac{1}{2 \sqrt{4}} 0,02=0,005$ & $14(45 \%)$ & 31 \\
\hline
\end{tabular}


The proportion of teacher students did not answer or answered that they did not know what dx is lower than the rate only at $10 \%$ of students. The research of Chung Thi Kim Hanh (2005) showed that 94/100 of student responses show that they did not know what dx means.

The proportion of teacher students wrote the formula $d y=f^{\prime}(x) d x$ also accounts for more than half. However, this difference was significant compared to the success of the students in research 1/100 of Chung Thi Kim Hanh (2005). The reason for this evolution was differential equations at university level as in an answer below.

b) Ban hãy tinh $d x$ và $d y$

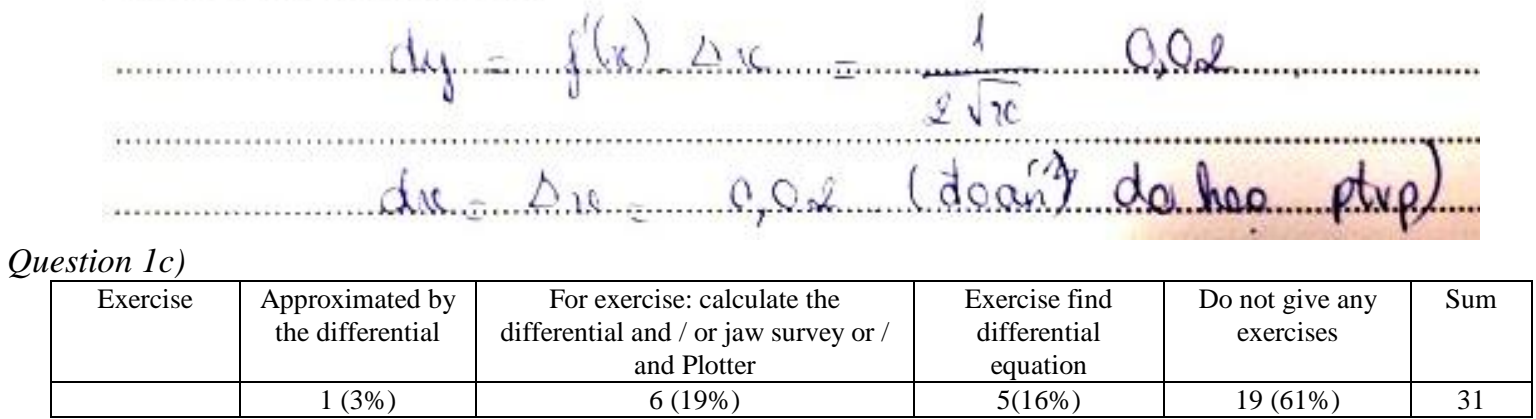

Question 2: There were no students who used the differential with level 1 to answer the question, although this is a type of primary task in the textbook Algebra and Calculus in class 11.

Experimental results show that the understanding of symbols $\mathrm{dx}, \mathrm{dx}$ and dy of teacher students in Mathematics Education did not progress much from the students in high schools. Also, the significant percentage of the students did not give the answer in the question (for example: $61 \%$ of students did not mind exercises involving the differential), some teacher students gave reasons as follows:

\section{Nếu không tính được $\mathrm{d} x$ và $\mathrm{d} y$, bạn hãy giải thich tại sao mình không thề trả lời:}
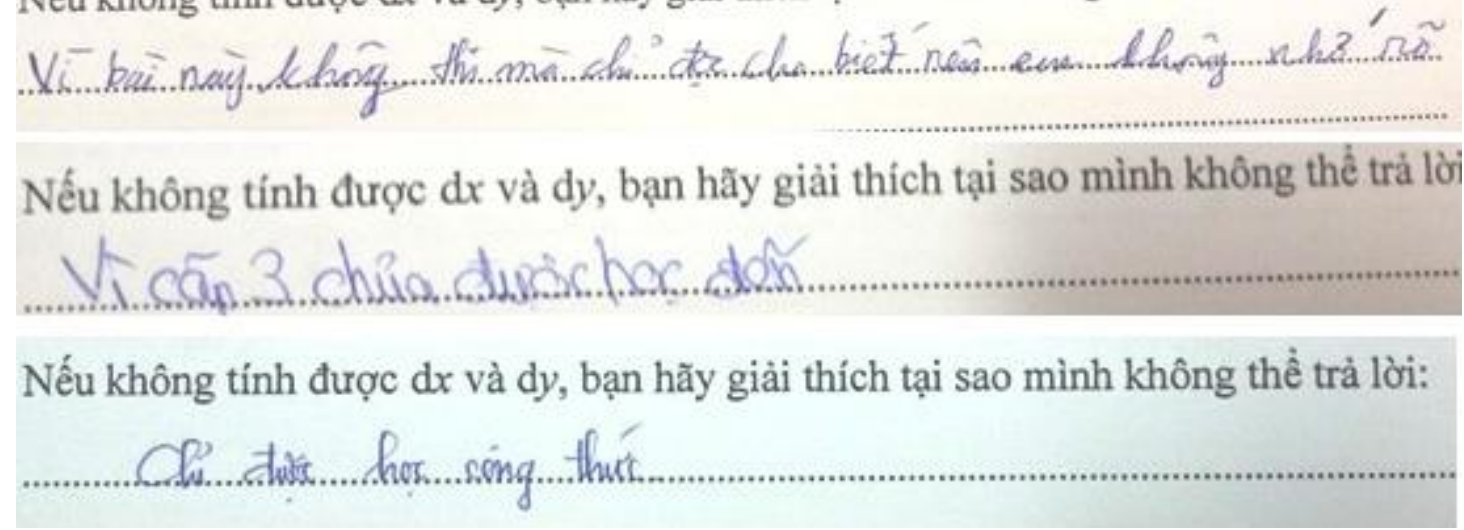

These reasons revealed that the cause of the students did not comprehend the essence of the concept of differential, as well as other important concepts of calculus came from the ways of teaching. The contents of examinations have contributed to the absence of the important knowledge in the curriculum.

\subsection{A situation related to solving problems}

Leibniz's symbol of differential was first used when solving the tangent of the curve. In his calculus textbook, Stewart (2012) also made it clear that differential idea may stem from the recognition with approximation curve with its tangent line in the next neighborhood point. From that idea, we designed a situation with the following issues:

Given the function $\mathrm{y}=\mathrm{f}(\mathrm{x})$ with its graph $(\mathrm{C})$ and a point $\mathrm{M}_{0}$ with $\mathrm{x}_{0}=1$. A straight line (d) has exposed the equation $y=2 x-1$ (C) at the point $\mathrm{M}_{0}$. (See figure below).

Knowing that the value $\mathrm{x}$ increases by a small amount from 1 to 1,001 .

Graph 


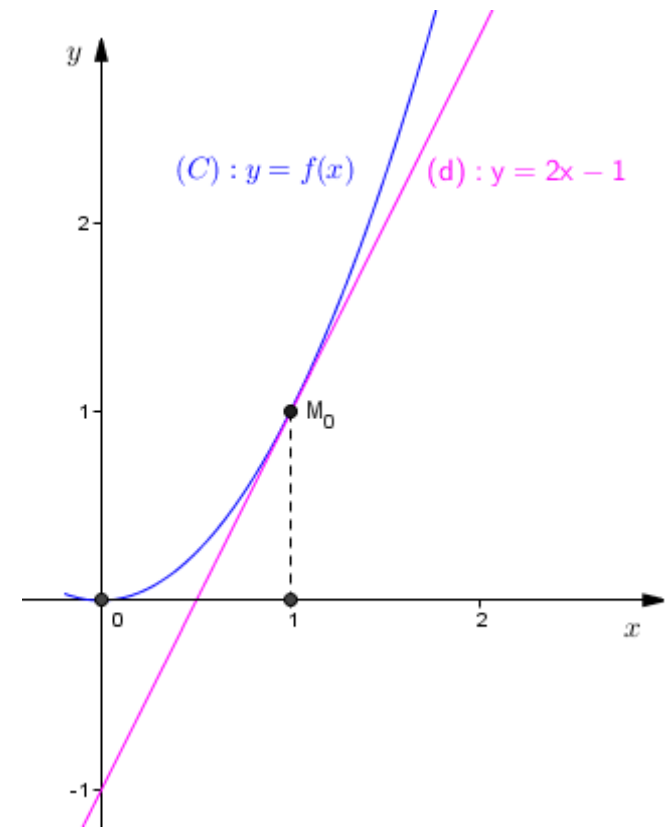

Calculate the approximate amount corresponding increase of value

The answer of the group (stating how to calculate):

By the use of the mathematical properties, to explain why groups answer:

\subsubsection{Pedagogical choices for situations}

Pedagogical choice 1: Representation of functions (curve function and its tangent at $\mathrm{M}_{0}$ )

In our experiment, we only chose the function curve represented by the graph; the tangent function is represented by graphs and algebraic formulas. The choice of situations may facilitate students to use tangents instead of curves when calculating the increment of the dependent variable $\mathrm{y}$.

Pedagogical choice 2: The requirement with the accuracy or approximation of $\Delta y$

We selected the approximation requirement. This choice could allow approximation strategies to appear.

We can expect the following strategies:

- Strategy $1(S 1)$ : Calculate the increment of the variable y by performing its curve. Because the curve function has no analytical expressions, this calculation should have done the measurements. We predict, students can first think of this strategy, but they will leave it to find a better strategy because the measurement for students in Vietnam ended in early high school grades.

- Strategy 2 (S2): Based on the shape of the curve, students give content analytical expressions of the curve. From this formula, they calculate the increment $\Delta y$

- Strategy 3 (S3): From a straight line close to the curve in the vicinity of $\mathrm{x}_{0}=1$, the students can find approximately the increment $\Delta y$ on the tangent. Hence, we can go to the results: $\Delta y=(2 x-1)-\left(2 x_{0}-1\right)=2\left(x-x_{0}\right)=2 \times 0,001=0,002$

We expected some answers by the third strategy to appear most. This strategy exposes geometric ideas related to the differential: The tangent approximates the curve in neighboring contacts.

\subsubsection{An analysis of experimental results}

In this situation, we divided 31 students into 15 groups: 14 groups with two students and one group with three students.

\begin{tabular}{|c|c|c|c|c|c|}
\hline Answers in & $\begin{array}{c}\text { S1- graph } \\
\text { measurement }\end{array}$ & $\begin{array}{c}\text { S2- find the formula } \\
\text { of the curve }\end{array}$ & $\begin{array}{c}\text { S3- approximately equal tangent } \\
\text { (differential idea) }\end{array}$ & $\begin{array}{c}\text { No } \\
\text { answer }\end{array}$ & Sum \\
\hline some groups & 0 & 6 & 8 & 1 & 15 \\
\hline
\end{tabular}

Thus, with the pedagogical choices, the $\mathrm{S} 3$ was the most popular choice. For example, 
Câu trá lời của nhóm (ghi rõ các buớc tính toán) :

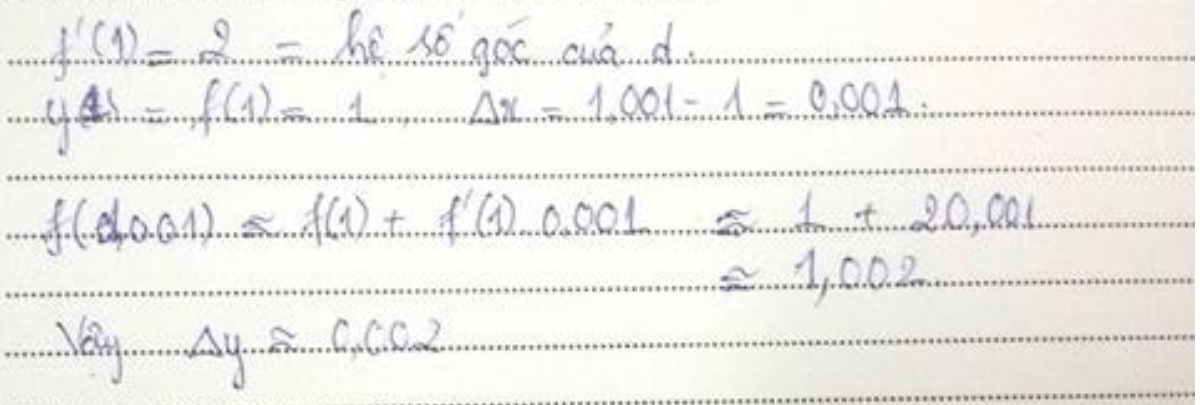

Bằng các sủ dụng các tỉnh chất toán học, giäi thich tại sao nhóm trả lời nhu vậy :

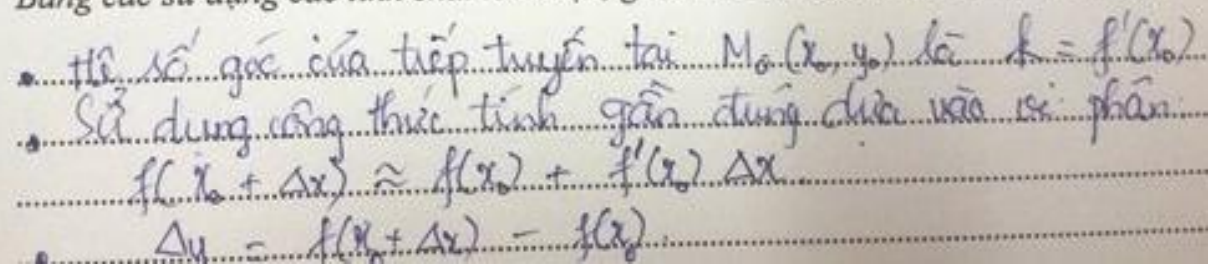

We also noted the competition between S2 and S3. This may be due to the selection of the shape of the curve in the graph. The kind of graph is very close to a branch of parabola- a familiar plot. This helps us adjust to this project in the future.

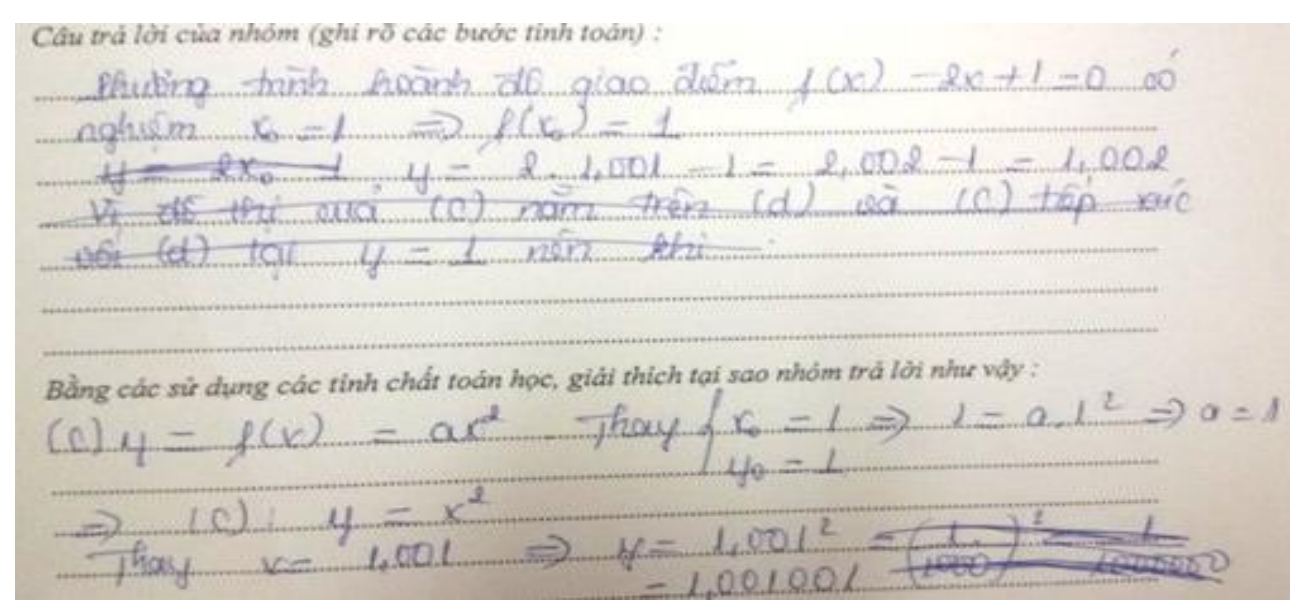

We also found some traces which we believe to be evidence of the students leave S1- graph measurement or S2finding formulas to switch S3- forming the geometric idea of the differential.

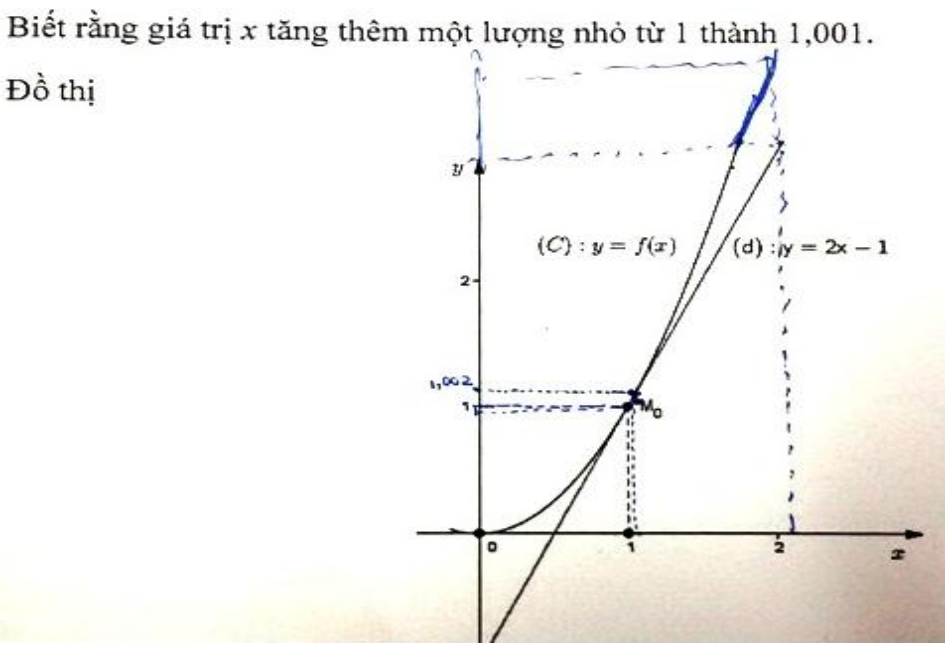


The final result of this group was S3 - the geometric idea of the differential.

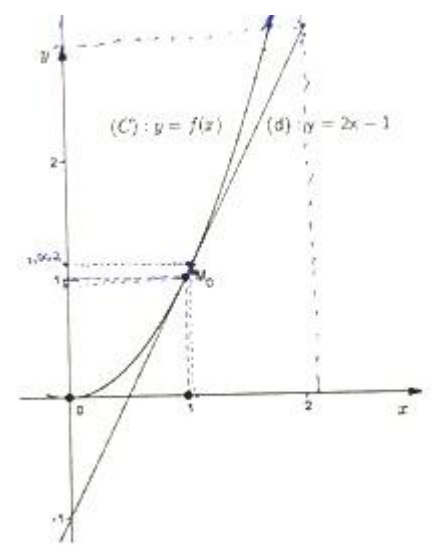

Hãy tính gần đưng lượng tăng tương ứng của giá trị $y=f(x)$

Câu trà lờ cúa nhóm (ghi rõ các bước tính toán) :

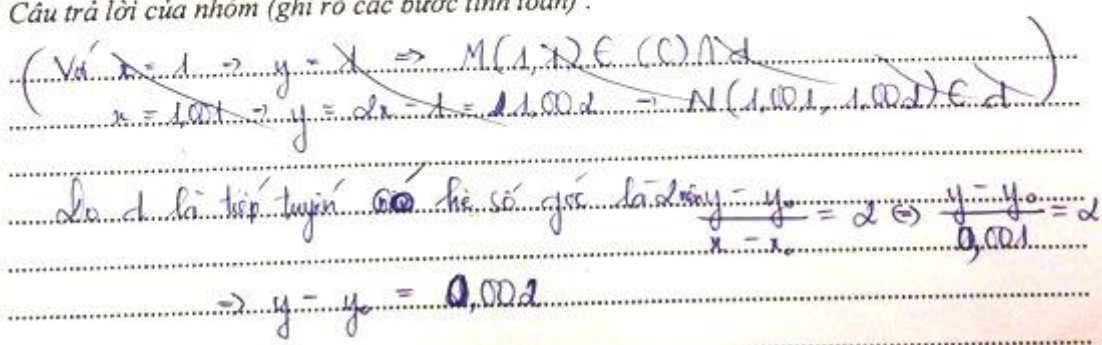

\subsection{Phase 3: Introduce the concept of differential}

We restated the definition of differential by clarifying its geometric meaning through a ballot delivered to the students with the following contents:

Given the function $y=f(x)$ has a graph $(C)$ and a point $M_{0}$ with $x_{0}=1$. Given a straight line (d) have exposed the equation $y=2 x-1$ contacting $(\mathrm{C})$ at the point $\mathrm{M}_{0}$. Knowing that the value $\mathrm{x}$ increases by a small amount from 1 to 1,001. Approximate the increasing amount of value $y=f(x)$ respectively.

The notations $\Delta \mathrm{x}, \Delta \mathrm{y}, \mathrm{dx}$ and dy can be illustrated by the following figures:

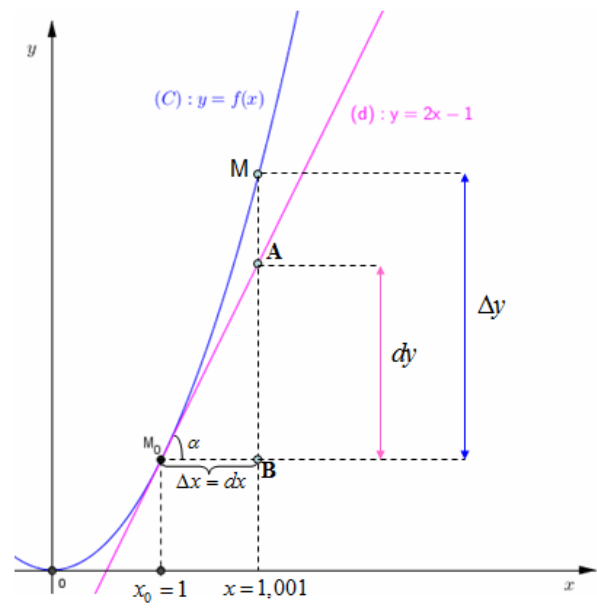

When $\Delta \mathrm{x}=\mathrm{x}-\mathrm{x}_{0}=0,001$ is small, there is no accurate way.

$\Delta \mathrm{y}=\mathrm{f}(\mathrm{x})-\mathrm{f}\left(\mathrm{x}_{0}\right)=\mathrm{MB}$, it is common to calculate dy through the tangent $(\mathrm{d})$ :

$\mathrm{dy}=\mathrm{y}(\mathrm{x})-\mathrm{y}\left(\mathrm{x}_{0}\right)=(2 \mathrm{x}-1)-\left(2 \mathrm{x}_{0}-1\right)=2\left(\mathrm{x}-\mathrm{x}_{0}\right)=2 \Delta \mathrm{x}=2 \times 0,001=0,002$

When $\mathrm{x}$ changes $\Delta \mathrm{x}=0,01$ from the point of $\mathrm{M}_{0}$, the $y=f(x)$ respectively increase the values close to 0.002 . In general, we consider the curve (C) with the equation $y=f(x)$ 
We denote: the increment of the variable $\mathrm{x}$, which indicates a slight change of $\mathrm{x} ; \Delta y=\mathrm{f}(\mathrm{x}+\Delta \mathrm{x})-\mathrm{f}(\mathrm{x})$

Is the increment of the function $\mathrm{y}=\mathrm{f}(\mathrm{x})$, it charts the changes in value of the function $y=f(x)$ when $\mathrm{x}$ changes a small amount. We define $d x=\Delta x$ the differential of the variable $\mathrm{x}$; dy is a differential of a function. dy is the change in the $\mathrm{y}$ value of the tangent to the curve at $\mathrm{P}$ when $\mathrm{x}$ changes a small amount. To calculate dy, we consider the triangles PSR, we have: $\tan \alpha=\mathrm{RS} / \mathrm{PS} \Rightarrow d y=\mathrm{RS}=\tan \alpha \times \mathrm{PS}=f^{\prime}(x) \Delta x=f^{\prime}(x) d x$

(Note: the slope of the tangent $\tan \alpha$ equals the derivative $\mathrm{f}^{\prime}(\mathrm{x})$ at the contact point $\mathrm{P}$ )

When $\Delta \mathrm{x}$ is small, $d y \approx \Delta y$

We have the following important things: When $\Delta x$ is smaller and smaller, $\Delta y$ and dy are close to equal, so $d y=f^{\prime}(x) \cdot d x$.

\subsection{Questions after the experiment}

To observe the change of student knowledge through the situations and questionnaire reintroducing the concept of differential, we asked teacher students with the question simlilar to the one in phase 1 .

Given the function $y=f(x)=\sqrt{x}$ with its graph (C) and a point $\mathrm{M}_{0}$ with $\mathrm{x}_{0}=4$. Given a straight line (d) contacts $(\mathrm{C})$ at the point $\mathrm{M}_{0}$. Knowing that the value $\mathrm{x}$ increases by a small amount from 4 to 1,001 .

a) Approximate the increasing amount of value $y=f(x)$ respectively.

b) Do not use the portable computer, you just approximate $\sqrt{4,001}$.

Experimental results show that 13/15 groups of teacher students successfully used the idea "The tangent approximates the curve in neighboring contacts" or the differential concept to answer the questions correctly. For instance,

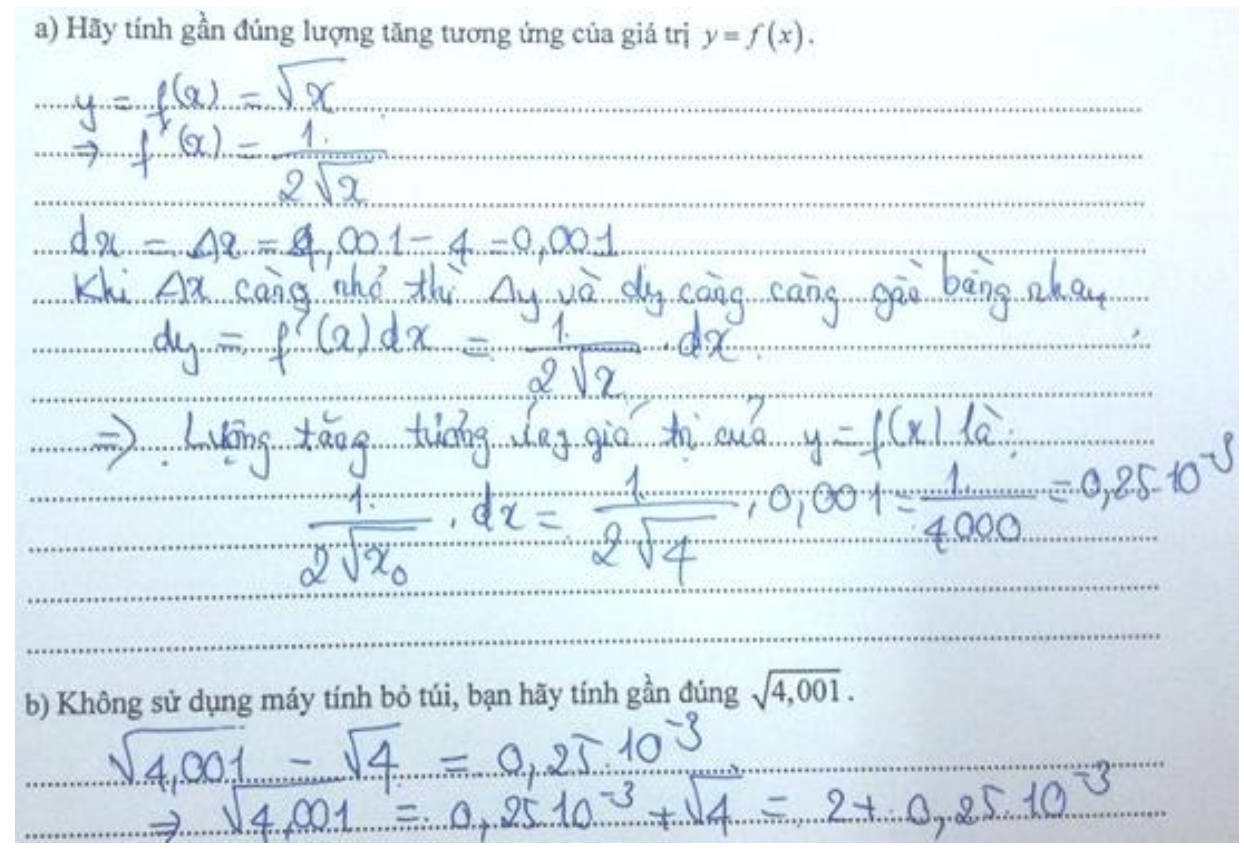

\subsection{Stage 4: Questions for discussion and review}

To sum up in terms of teaching methods, we found questionnaire content discussed below for 31 students. We also conducted a similar experiment for high school students who learned the concept of differential (in both the standard and advanced programs).

- Result analysis shows: No school students (of 200 students) understood the meaning of differential and its role in the approximation. Especially, they did not remember $d x=\Delta x$.

- A survey in a class (including 42 students, divided into 21 groups) showed that 15/21 groups accepted a tangent instead of a function when calculating the increment of the function with variable small increments.

- With the geometric meaning of the differential introduced by researchers, all groups were successful when applying the differential to approximate. 


\section{DISCUSSION QUESTIONS}

According to you, how should teaching the concepts of calculus is held to improve the status like this? We statistically some opinions of students in the following table:

\begin{tabular}{|l|c|}
\hline \multicolumn{1}{|c|}{ Ideas } & Sum \\
\hline $\begin{array}{l}\text { Steming from the problems that give the meaning of the analytic knowledge (especially the problems } \\
\text { in physics) }\end{array}$ & 12 \\
\hline $\begin{array}{l}\text { Using visual representations (such as graphs, photographs, ...) to help students approach the meaning } \\
\text { of knowledge }\end{array}$ & 12 \\
\hline Students should work in groups & 9 \\
\hline $\begin{array}{l}\text { Teachers should evaluate students with the homework to understand the concepts and apply them in } \\
\text { practice (reducing the computational exercises) }\end{array}$ & 2 \\
\hline
\end{tabular}

Through this situation, 12/31 (39\%) teacher students have admitted the necessity of teaching in situations that bring the meaning of knowledge. They also expressed that the problems of ordinary calculus with problems in physics, so they may stem from physical problems. This view of the students facilitated the design of teaching by modelling.

With the same proportion, 12/31 (39\%) students realized the importance of performing analytical concepts on geometric aspects (especially graphs). This visual fulcrum helps learners easily access to more abstract concepts of calculus.

In addition, 9/31 (29\%) students saw the benefits of working groups. 2/31 students said that teaching, especially when evaluating students, should remove the existing computing tasks and increase questions (or tasks) which require students to understand the concepts.

After discussions, we summarized some key points as follows:

- Using situations of problem-solving because they allow to mention the significance of knowledge.

- Through the experiments and observations on the picture, try to clarify the meaning of knowledge about these aspects: geometry, algebra and arithmetic.

- Students should work in small groups (2-3 students) on a situation of problem-solving.

- The orientation of the new program-makers, through teaching mathematics, in addition to providing knowledge, students need to be gradually formed:

+ Ability to solve the problems.

+ Ability to compute.

+ Ability to cooperate, including language ability and critical capacity.

Our proposals today will guide our design appropriate teaching calculus with the orientation of the new program.

\section{CONCLUSION}

Stewart (2012) said that teaching calculus should help students understand the meaning of knowledge. A part of research that we have carried helped future teachers realize the importance of teaching situations of problemsolving, the graph observation and number experiments, and the organization of working in groups. Hence, these ways help students dominate the meaning of knowledge. At the same time, through teaching methods as well as problem-solving situations, teachers can help students form important abilities such as problem-solving ability and ability to cooperate.

\section{REFERENCES}

[1]. M. Artigue, Réformes et contre - réformes dans l'enseignement de l'analyse au lycée (1902 -1994), Les Sciences au lycée, p. 195 215, INRP, 1996

[2]. J. Stewart, Calculus: Early Transcendentals, $7^{\text {th }}$ edition, Brooks/Cole Cengage Learning, 2012.

[3]. N.B. Kim, Methods of teaching mathematics, Hanoi: Publishing house of Education, 2010

[4]. C.T.K. Hanh, A research on teaching the concept of differential in high schools, Master thesis, Can Tho University, 2015.

[5]. T.L.C. Khanh, la notion d'intégrale dans l'enseignement des mathématiques au lycée: une el tude comparative entre la France et le Vietnam, thèse en Didactique des Mathématiques, Université Joseph Fourier, Grenoble, 2006.

[6]. L.V. Tien, Some typical situations in teaching mathematics, Ho Chi Minh city: Publishing house of The national university of Ho Chi Minh, 2005.

[7]. L.T.B.T. Trung, Secondary Mathematics Knowledge in Econometrics, VNU Journal of Science: Education Research, ISSN 08668612, Vol. 31, No. 4, p 26-35, 2015.

[8]. L.T.B.T. Trung, Notion de limite et décimalisation des nombre réels: une ingénierie didactique, Petit $x n^{0} 99$, p 33 -56, ISSN 07599188, IREM de Grenoble, 2015. 